\title{
A Structure Analysis and Data Modeling of Telecom Product Based on Product Lifecycle Management
}

\author{
Xuefeng Zhao and Huaying Shu \\ School of Economics and Management, Beijing University of Posts and \\ Telecommunications, Beijing 100876, P.R. China tony.bupt@gmail.com shuhy@bupt.edu.cn
}

\begin{abstract}
This paper analyzes the necessity and requirements of switching from service-oriented operations to product-oriented operations in telecom industry, which helps to solve the conflict between more and more homogeneous telecom services and individualized customer demands. Then this paper puts forward a comprehensive definition of telecom product, and presents a structure framework of telecom product consisting of 8 ingredients: telecom service, information content and application, tariff, target market, brand, channel, customer service and supplementary resources. Meanwhile, this paper analyzes the process framework of telecom product lifecycle management and divides it into 4 phases: planning, developing, approving and publishing and improving or withdrawing. The complete concept data model is analyzed and gradually shaped in the UML language in the 4 phases.
\end{abstract}

Keywords: Telecom product, Product life cycle system, Data modeling, Business information Entity, Model driven architecture

\section{INTRODUCTION}

As rapid advancement of telecom technology and increasingly drastic competition in telecom market of China, services different telecom operators offer are more and more homogeneous, and vicious price war has become the primary means of competing. To satisfy individualized customer demands and maintain higher profitability, telecom operators have to switch from service-oriented operation to product-oriented operation. However, questions like what is exactly telecom product, what is its structure and how to model it in operation support system remain to be solved.

This paper puts forward a comprehensive definition of telecom product, and presents a structure framework of telecom product consisting 8 ingredients. Then this paper analyzes the process framework of telecom product lifecycle management and divides it into 4 phases: planning, developing, approving and publishing and improving or withdrawing. After that, the complete concept data model and logical data model of telecom product are discussed and gradually shaped in the UML language during the 4 phases. This paper concludes by exploring the application of this data modeling approach in a telecom operator and its operation support system. 


\section{STRUCTURE FRAMEWORK OF TELECOM PRODUCT}

The definition of telecom product is still vague and controversial in the industry, so before discussing the structure of telecom product, it's necessary to clarify several relating concepts. One of the authoritative definitions of telecom product is given by eTOM (Enhanced Telecom Operation Map) framework presented by TeleManagement Forum, in which it's defined as "Product is what an entity (supplier) offers or provides to another entity. Product may include service, processed material, software or hardware or any combination thereof. A product may be tangible (e.g. goods) or intangible (e.g. concepts) or a combination thereof. However, a product ALWAYS includes a service component."[1] This definition is not from the point-ofview of business but from the perspective of telecom operation support system development.

This study defines related concepts mainly from the perspective of business, and the definitions are expected to be easily understood by both marketers and system developers.

- Telecom product is what a telecom operator offers under a brand to satisfy communication and information needs of specific segmented customers. Telecom product is based on telecom service, attaching tariff, information content/application, channel, customer service and supplementary resource.

- Telecom service is a function telecom networks provide, and it can be divided into 2 categories: basic telecom service and supplementary telecom service which is dependent on basic telecom service.

Based on the definition of telecom product, the structure framework of telecom product is illustrated in Figure 1.

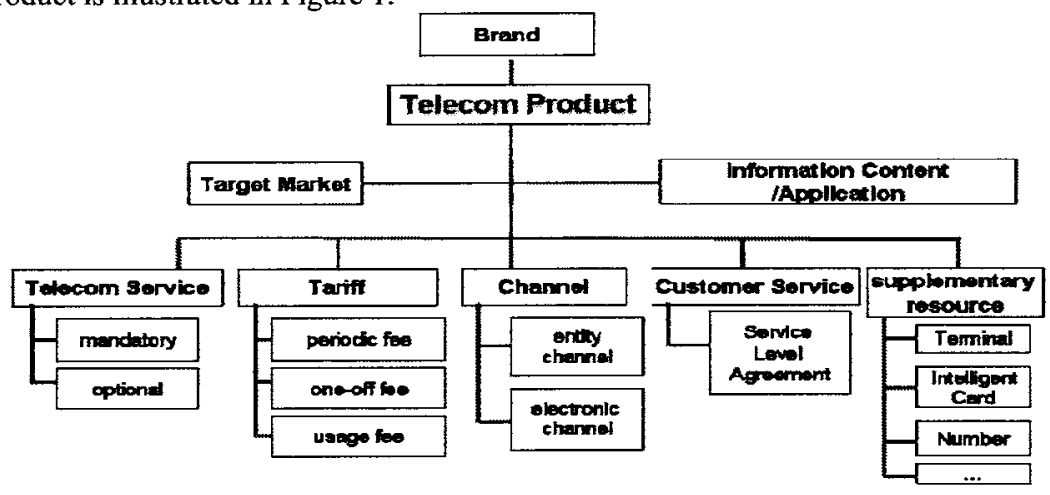

Figure 1. Structure Framework of Telecom Product 


\section{DATA MODELING OF TELECOM PRODUCT BASED ON PRODUCT LIFECYCLE MANAGEMENT}

Conceptual data modeling of telecom product will be discussed in this section after establishing the definition and structure framework of telecom product. From the decision to develop a new telecom product to withdrawal of this telecom product, there are many phases during the process of product management within a telecom operator. By deeply examining the typical processes of product management of Chinese telecom operators, this paper extends the process of product lifecycle management of eTOM and divides it into 4 phases: planning, developing, approving and publishing and improving or withdrawing. These phases could be further divided into 13 sub-processes: objective analysis, market positioning, planning of telecom services bundling, planning of tariff, developing of new telecom services, planning of sale channels, planning of customer services, planning of complementary resources, testing of the product, delivery of the product, marketing promotion, assessment of product performance and improving or withdrawal.

This paper adopts process-driven data modeling approach to model telecom product and the conceptual data models are mainly derived from Shared Information/Data Model (SID) [2]. In the following 4 sections, each phase of product lifecycle management is analyzed and this phase's telecom product conceptual model will be given in the UML language.

\subsection{Phase of Telecom Product Planning}

In this phase, the idea and blue print of a new telecom product will be put forward according to customers' needs. It involves lots of market research and data mining to find customers' unsatisfied needs. The work of this phase is described by the entity of product plan in the data model, as illustrated in Figure 2.

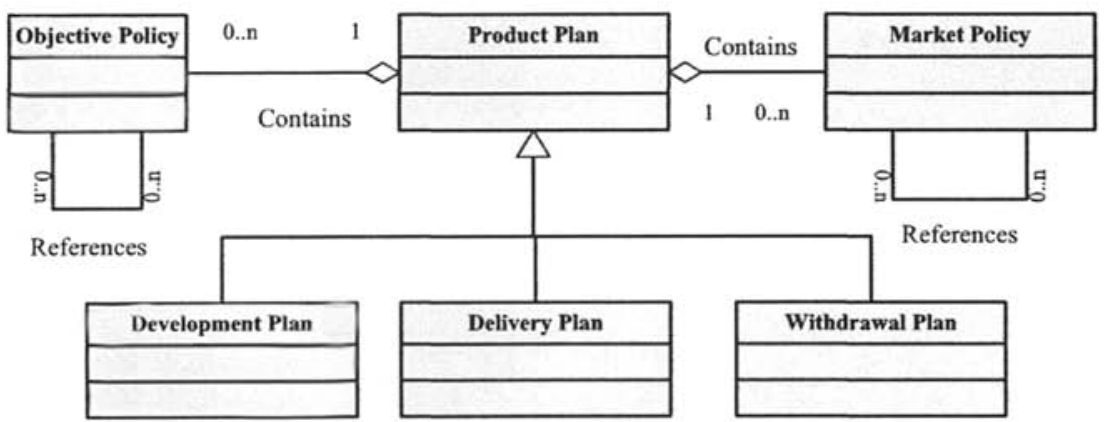

Figure 2. Class Diagram of Planning Phase 


\subsection{Phase of Telecom Product Developing}

This phase is the core of overall product lifecycle management, and related work involves determining the product elements of telecom services, complementary resources and customer services. Designing the tariff of the new product is also needed to be done according to market policy determined in the previous phase. This phase involves the following entities: product specification, product offering, product offering price, product offering terms. Among these entities, product specification is the core entity, and its class diagram is shown in Figure 3.

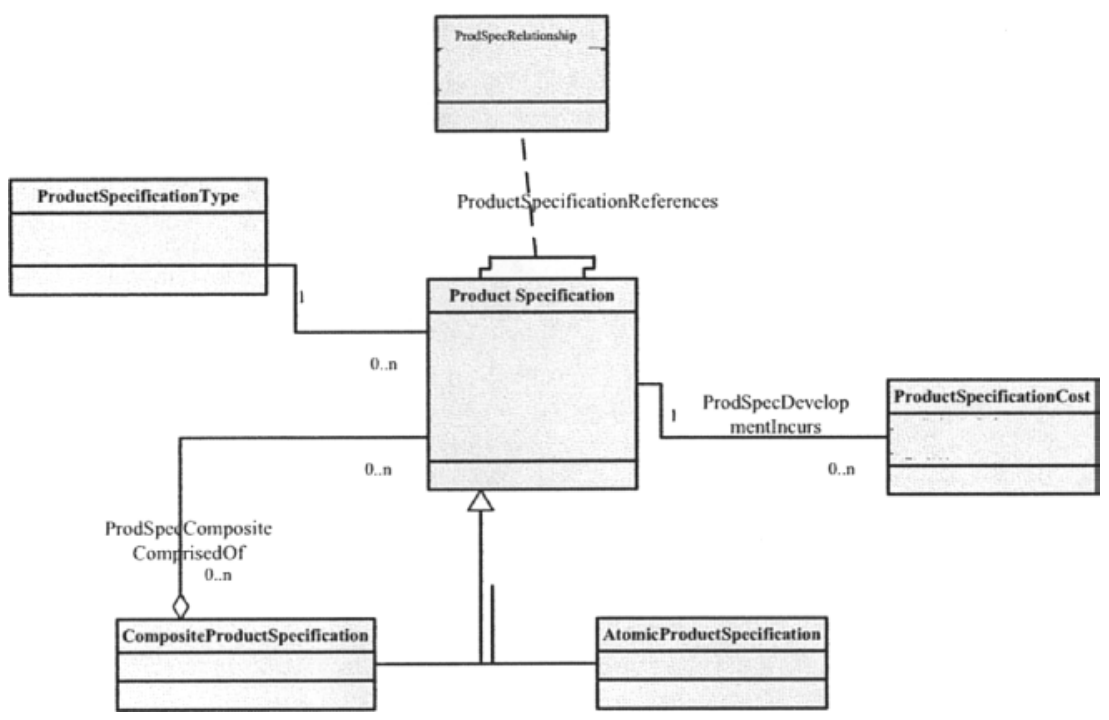

Figure 3. Class Diagram of Developing Phase

\subsection{Phase of Telecom Product Approving and Publishing}

Before publishing of the new telecom product, it must be submitted to the manager layer, and undergone a strict approving process. The managers will check whether the network and operation support system are ready. If the new product is approved, it will be published into the operator's product catalog and subscribers then could buy the product. So far, the telecom product has its complete properties as shown in Figure 4. 


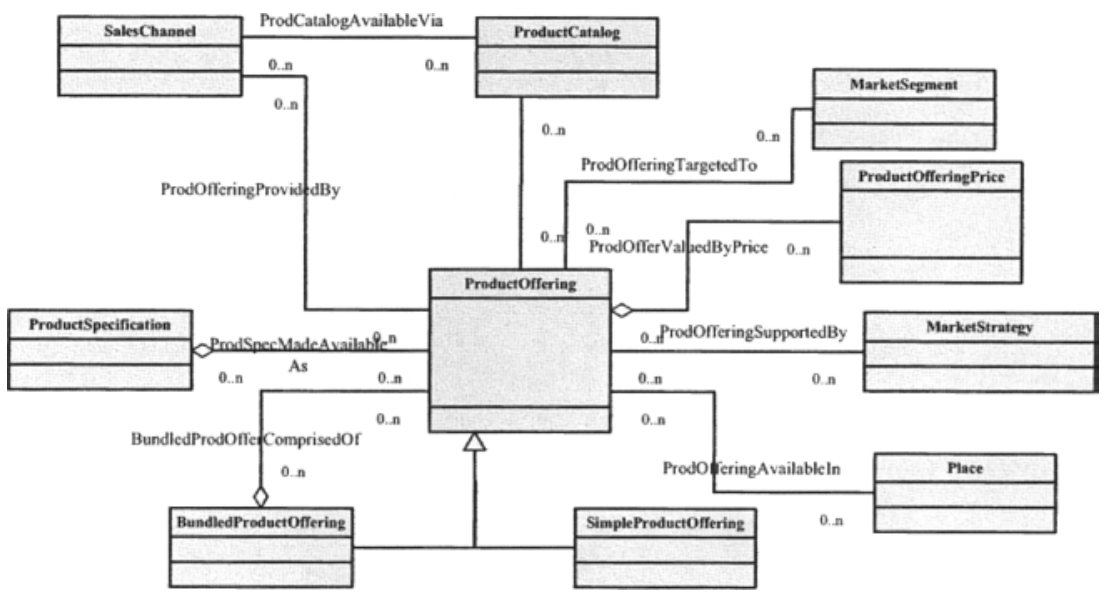

Figure 4. Class Diagram of Approving and Publishing Phase

\subsection{Phase of Telecom Product Improving and Withdrawing}

In this phase, the operation support system should collect data about product subscription and performance in real-time, and generate reports periodically. The manager layer could determine improving or withdrawing the product according these reports.

\section{CONCLUSIONS}

In this paper, we have given a comprehensive definition of telecom product, and then presented its structure framework. Moreover, we have modeled the telecom product in a process-driven approach, but the model is conceptual model, in further research it should be extended into logical model.

\section{REFERENCES}

1. TeleManagement Forum, The Business Process Framework for the Information and Communications Services Industry GB921 Version 6.1, in Enhanced Telecom Operation Map (eTOM) (2005), p.63.

2. TeleManagement Forum, Business View Concepts, Principles, and Domains GB922, Shared Information /Data (SID) Model (2005). 